\title{
The Application of Rubber Seed as Activated Carbon for Removal Methylene Blue by Using Microwave Heating
}

\author{
Ema Luvita Sari ${ }^{1}$, M. Faizal ${ }^{2 *}$, Tuti Indah Sari $^{2}$ \\ ${ }^{I}$ Graduate Program Student, Chemical Engineering Magister Program, Sriwijaya University, Indonesia \\ ${ }^{2}$ Dept. of Chemical Engineering, Faculty of Engineering, Sriwijaya University, Indonesia \\ ${ }^{3}$ Dept. of Chemical Engineering, Faculty of Engineering, Sriwijaya University, Indonesia \\ *Coressponding author email : ema.luvita@gmail.com \\ Article history

\begin{tabular}{llll} 
Received & Received in revised form & Accepted & Available online \\
10 July 2019 & 30 March 2020 & 31 March 2020 & 31 March 2020 \\
\hline
\end{tabular}

\begin{abstract}
Activated carbon prepared using natural rubber seeds for removing methylene blue. To estimate the interaction of adsorbates towards the adsorbent in this study applied adsorption studies. Freundlich and Langmuir isotherm has been used to predict adsorption model in this work. The study appeal two mechanism of radiation carbon, conventional and microwave heating, with various of impregnation ratio, adsorbent mass and radiation time. Carbon was activated by using various of $\mathrm{KOH}$ using conventional and microwave heating. The best yield was shown by activated carbon which dried using microwave heating in IR 1:1.5. The percentage of adsorption and $q e$ value were $3.486 \mathrm{mg} / \mathrm{g}$ and $69.72 \%$, respectively. The best result of adsorption $\mathrm{MB}$ using various of mass adsorbent was shown in 0.4 gr. The percentage was $90.24 \%$. The Langmuir isotherm was suitable to this work, the $n$ value was 0.5338 . This study was well fitted with the pseudo-second-order. The calculation of qe( $\left(_{\exp }\right)$ was approach to the qe (cal) in pseudo second order.
\end{abstract}

Keyword: Rubber seed, Activated carbon, Microwave Radiation, Methylene blue

\section{Introduction}

Methylthioninium Chloride is a scientific name of Methylene blue (MB). Its common use in some industries that use dyes as one of the material to do the process. However some harmful effects can cause the population and animals nearby the industrial process due to the water that contain dyes was not treat properly [1]. For about $5-10 \%$ of dye wares are occur in industrial environment for each production process [2-4]. The wastewater from the coloring process contain high number of air pollution, specifically, BOD and COD[3]. Even in a small amount of dye in water is very visible. To release these dyes waste in the environment is concerned for both toxicological and aesthetical reasons [5]. The impact of this process can be causes some medical risk for organism, such as methemoglobinemia, cyanosis and convulsions [6]. In case the dyes was inhaled or swallowed some poisoning symptoms could be appear [8]. Several treatment has been done to minimize the wastewater of dyes such as membrane filtration, biodegradation, liquid-liquid extraction, advanced oxidation, electrofotation, coagulation/flocculation, ozonation, and adsorption. Neverthless, each process has theirs capacity to omit the water that contain dyes.

Adsorption process is selected not only its simple to application but also its highly effective for removing pollutant from waste water. Several research declare that activated carbon can be use for removal MB [1, 2, 9-11].

In years conventional heating just the most interest process that use to prepare activated carbon. Nowadays, the using of microwave technology is getting interest. The benefits of microwave heating are such as, an intense thermal gradient through the char, energy saving and short processing times.

The purpose of this study is to use the low cost material for activated carbon and to activate the carbon using conventional and microwave heating to find out the characteristic of activated carbon by kinetics model and isotherm adsorption.

\section{Material and methods}

\subsection{Adsorbent}

To produce activated carbon, the rubber seed gained from rubber plantation at Banyuasin, South Sumatera. It was shelled to get the rubber seed. For remove soluble impurities and dirt the rubber seeds were washed repeatedly. Before dried using oven, the seed are dried in the sun for almost 7 hours to reduce water content. In order to get the result of carbonization are more optimal, during 2 hours the rubber seed were dried in oven at $600^{\circ} \mathrm{C}$ before its crushed. To get rubber seed powder, it grinded using mortar till the powder collected in $35 \mathrm{MESH}$ of British Standard Sieves (BSS). The various of $\mathrm{KOH}$ was mixing with $1 \mathrm{~g}$ carbon powder 1:1, 1:1.5, 1:2 and 1:2.5. The carbon powder soaked for around $24 \mathrm{~h}$ 
and it was rinsed apply filter paper with distilled water until reached $\mathrm{pH}$ 6-7 [20]. The washed powder was then dried in the oven for about 1 hours at $105^{\circ} \mathrm{C}$ and the other one dried using microwave heating in 5 minutes at 400 watt.The carbon powder that prepared for experiments was stored in an airtight plastic container. The activated carbon was kept in room temperature and ready to use for adsorption and characterisation.

\subsection{Adsorbate}

In this work, $\mathrm{MB}$ was produced from Darmstadt, Germany and used without purification. To get $1 \mathrm{ppm}$ MB solution, $1 \mathrm{~g}$ of MB powder was dissolved in a litre of distillate water. To run the experiments the $1 \mathrm{ppm}$ MB solution was diluted with distillate water. Its purpose to get the appropriate concentration of the working solutions. In each various of IR (impregnation ratio) applied $10 \mathrm{mg} / \mathrm{l}$ of MB.

To determine the concentration of MB using UV/VIS Spectrophotometer (Shimadzu UV-2450). To get the profile of absorbance-concentration, a standard samples were use for knowing the number of absorbance. Then it set to plot the calibration curve.

\subsection{Batch kinetic studies}

The batch experiments were carried out to measure the influence of various factors. A number of dye solution in each $50 \mathrm{ml}$ took as much as the experiments requirements. At the set time, a sample of dyes were taken using drop pipette from the shaker and to analyzed the absorbance a few droplet dye concentration was reading the amount of absorbance using an UV/VIS Spectrophotometer at $600 \mathrm{~nm}$. The calibration curve as reference to read the absorbance result. Adsorption experiments were took to know the graph of interaction between adsorbates with adsorbents by using isotherm and kinetics study. The equilibrium, $q$ e $(\mathrm{mg} / \mathrm{g})$, is defined by calculate the concentration of $\mathrm{MB}$ in appointed time

$q_{e}=\frac{\left(C_{0}-C_{t}\right) V}{W}$

And the adsorption efficiency i.e. \% of was calculated as

$\%$ adsroption $=\frac{\left(C_{0}-C_{t}\right)}{C_{0}} \times 100$

where $C_{0}$ and $C_{\mathrm{t}}(\mathrm{mg} / \mathrm{L})$ are the MB solution that take in initial and selected time interval, t, respectively. $V$ is to describe the volume of dyes that use in experiments (L) and $W$ is the number of mass adsorbent used $(\mathrm{g})$.

\section{Results and Discussion}

3.1 Effect of chemical impregnation ratio by using conventional heating

In several study activated carbon from rubber seed has been proven effective and have ability to adsorbe dyes. For specific time the curve achive equilibrium point, which mean the carbon has been reach the maximum ability to adsorbe dyes. Fig. 1 illustrate that the increasing of activator impact the amount of dyes adsorbed. It show that in IR 1:2.5 the qe calculation of MB adsorbed was $2.747 \mathrm{mg} / \mathrm{g}$. The percentage of dye removal was $49.91 \%$ for about 60 minute contact time. The increasing of $\mathrm{KOH}$ to prepare activated carbon using conventional heating work on the adsorption capacity to remove MB. As a result, $\mathrm{KOH}$ molecules can easily come into contact with the outer surface of the char. Indeed, the organic substances are converted into rich carbon structure which allows the material to be subjected to more $\mathrm{KOH}$ activation. In other words, the prodeuced char is more susceptible to chemical rection with $\mathrm{KOH}$, which consequently conducts to the formation of higher degree of mesopores and micropores. [25]

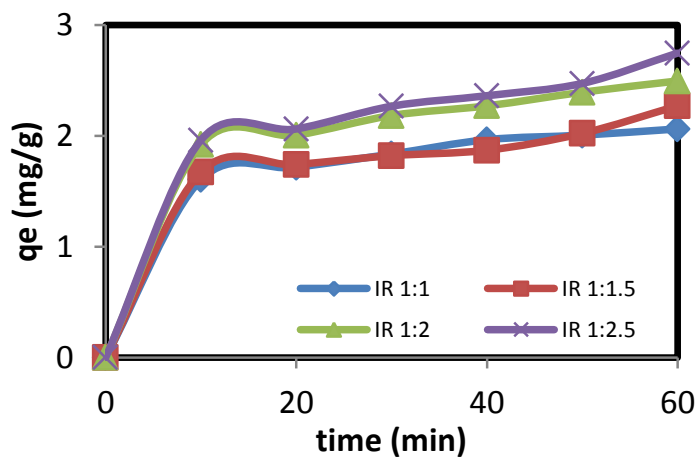

Fig. 1 Effect of various $\mathrm{KOH}$ using activated carbon by conventional heating. (Volume of MB solution = $50 \mathrm{ml}$; initial dye concentration $=10 \mathrm{ppm} \mathrm{MB}$ )

\subsection{Effect of chemical impregnation ratio by using microwave heating}

In this research, $\mathrm{KOH}$ was use to activate the carbon. The effect of IR $(1: 1 ; 1: 1.5 ; 1: 2$ and $1: 2.5)$ using microwave heating is effectively almost have the same result as conventional heating. In Fig. 2 represent the influence of various $\mathrm{KOH}$ in $\mathrm{MB}$ adsorption. It represented from IR $1: 1$ and 1:1.5 resulted an increase of amount of adsorbed MB from 2.851 to $2.971 \mathrm{mg} / \mathrm{g}$. The IR 1:1.5 shown the best adsorption equilibrium and percentage of adsorption $3.486 \mathrm{mg} / \mathrm{g}$ and $69.72 \%$ respectively. The amount of dyes removal increase with the small amount of activator.

Furthermore, the benefit of using microwave heating is the activation time can be extremely reduce, which in many cases represent a reduction in the energy consumption and cost as well. In addition, microwave heating has offered the another 
advantages i.e. higher heating rates, selective heating, greater control of the heating process, heating occurs throughout the carbon surface, no direct contact between the heating source and heated materials, and also reduced equipment size and waste. [24]

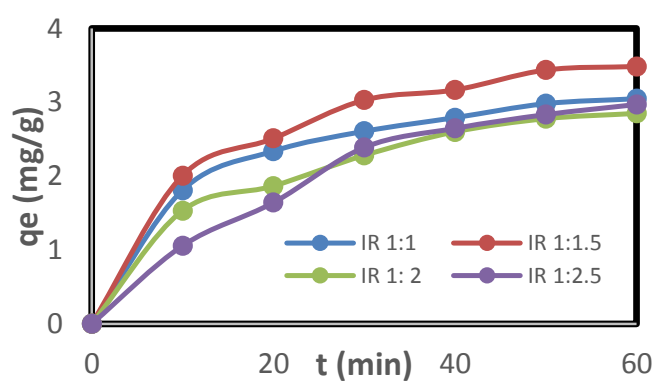

Fig. 2 Effect of various $\mathrm{KOH}$ using activated carbon by microwave heating (Volume of $\mathrm{MB}$ solution $=50$ $\mathrm{ml}$; initial dye concentration $=10 \mathrm{ppm} \mathrm{MB}$; activation time 5 minute; mass of adsorbent $0,1 \mathrm{~g}$ )

\subsection{Effect of various activation time of carbon}

The activation time was varied from 5 to 15 min and the use of $\mathrm{KOH}$ ratio was 1:1.5 using microwave heating method. From the Fig. 3 the result indicates that when the activation time is above 10 min, the activation is over because $\mathrm{KOH}$ is used up, and then adsorption of MB getting decrease. However, as the activation time arrives at its optimum value, adsorption and reflection of energy tends to balance and its reach the maximum ability to absorb. Microwave heating method has the properties of uniformly heating and rapidly heating rate, and thus, the sample may have more active sites in short time, resulting in high efficiency of activation. [12]

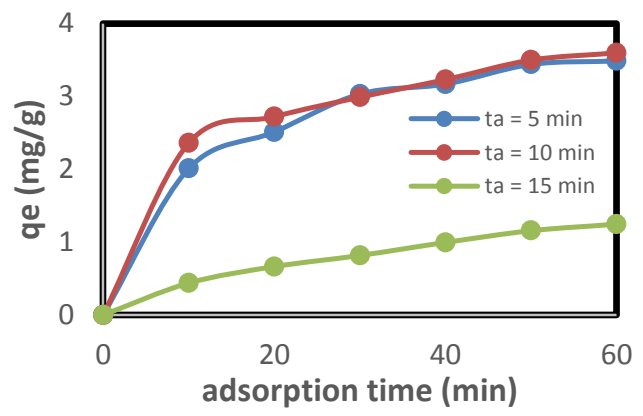

Fig. 3 Effect of avtivation time on MB removal, (Initial concentration of 10 ppm MB,; IR 1:1.5; mass of adsorbent $0.1 \mathrm{gr}$ )

\subsection{Effect of various mass of adsorbant dosage on $M B$ adsorption}

The percentage of MB removal getting higher with insentify of mass adsorbant. It was increased from $79.78 \%$ to $90.24 \%$ with the adsorbent mass 0.2 to 0.4 gram for which plots are presented in Fig 4 . The phenomenon of increase the percentage of $\mathrm{MB}$ removal with increase in adsorbent dose was due to the availability of more adsorbent surface for solute to adsorb. However very slow increase in removal beyond an optimum dose may be attributed to the attainment of equilibrium between adsorbate and adsorbent at the operating conditions [26]. In the adsorption process, the more carbon used, the greater yield of absorption occurs. Furthermore, large amount of carbon would increase the chance of molecule MB trapped. This is the consequence of availability carbon space to trap the adsorbates as the dosage of adsorbent increased.

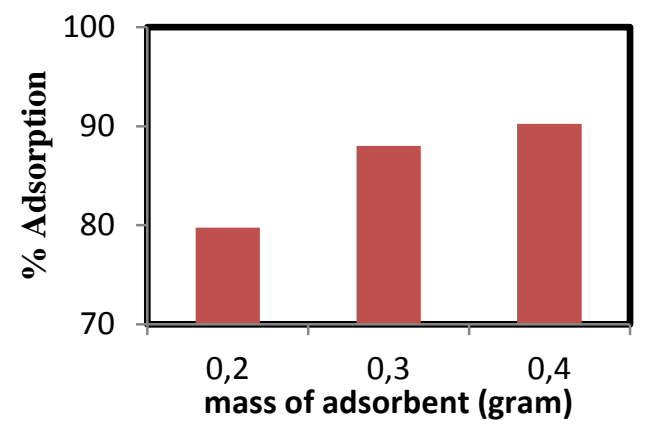

Fig. 4 Effect of adsorbent dosages on carbon active (Initial concentration of $10 \mathrm{ppm} \mathrm{MB}$; activation time 5 minute)

\subsection{Adsorption isotherm}

The adsorption isotherm is to represent the adsorption capacity of adsorbate in a constant temperature and it were calculated using molecular dynamics simulation[14]. Adsorption equilibrium is set when an adsorbate has been reach the contiguity with the adsorbent in adequate time.

There are two models normally use to illustrate the adsorption isotherm, in this study using two models of adsorption isotherm they were Freundlich and Langmuir choose to state interaction between adsorption and adsorbents[15,16]. Freundlich is an empirical relation among the concentration of solute on the surface and the adsorbates.

The Freundlich model, which describe the relationship between the amount of substance absorbed with total concentration of solution, can give as:

$$
\ln q_{e}=\ln K_{f}+\frac{1}{n}\left(\ln C_{e}\right)
$$

where $K_{\mathrm{F}}$ is freundlich equation to measure the adsorption capacity $(\mathrm{mg} / \mathrm{g})$ i.e. if the amount of adsorption capacity reach high yields means it correlation with $K_{F}$ value. Its related to each other. while $n$ is the intensity of adsorption in particular temperature. Its express an optimum adsorption of dyes removal on the adsorbent and a contact time, if $n$ value calculated higher than 1. [17] Otherwise, its conclude a chemical process, if the yield of $n$ is under 1. Whereas, $n$ is refers to unity, the adsorption is 
linear $[2,18,19]$. Fig. 5 shows that the regression coefficients on Freundlich isotherm fittings for MB removal. The result was 0.9959 . The yield of $n$ on Freundlich isotherm model was 0.5338 for MB and the adsorption capacity $\left(K_{F}\right)$ is 0.2744 for $\mathrm{MB}$, which showed the MB adsorption was favourable. It indicates the physic adsorption occur in multilayer.

The Langmuir model was express as:

$$
\frac{C_{e}}{q_{e}}=\left(\frac{1}{K_{L} q_{m}}\right)+\frac{C_{e}}{q_{m}}
$$

$K_{L}$ (values for Langmuir constant to indicates the extent of interaction between adsorbate and adsorbent which can conclude if the value was small means a weak interaction $(1 / \mathrm{mg}))$, Its predicted from the plot between $C_{\mathrm{e}} / q_{\mathrm{e}}$ versus $C_{\mathrm{e}}$. $q \mathrm{~m}$ (maximum volume of the monolayer adsorbed) $(\mathrm{mg} / \mathrm{g})$

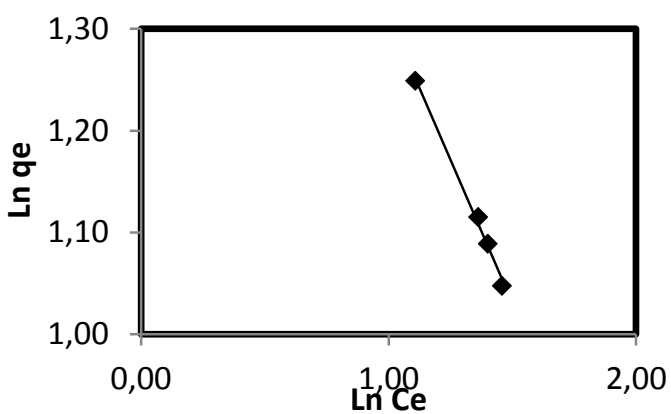

Fig. 5 Freundlich Isoterm Plot

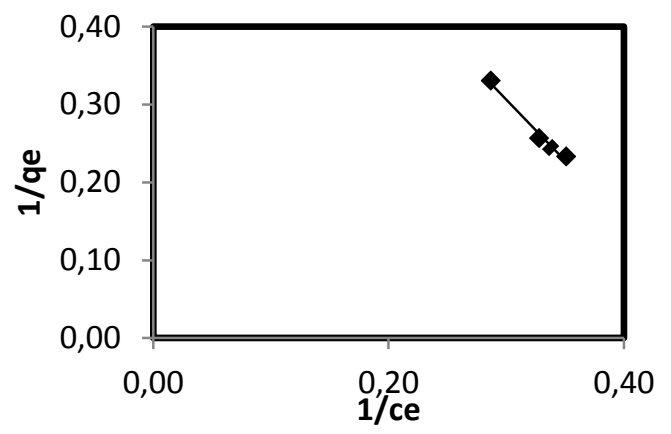

Fig. 6 Langmuir isoterm plot

The adsorption equilibrium show that the langmuir isotherm model was proper in this work. From Fig. 6 was interpreted the maximum monolayer adsorption capacity, $q_{m}$, assumed to be an ideal solid surface to adsorb the adsorbate. The adsorbate binding is handle as a chemical reaction between the adsorbate molecule and empty site of the sorption system. The coefficient regression, $q_{m}$ and $K_{L}$ value of MB was $0.9841,0.6340$ and 2.0225, respectively. From the result this study was fitting with both Freundlich and Langmuir isotherm model based on the value of coefficient regression.
Compared with previous study [23], the use of rubber seed as the activated carbon prepared in this work was relatively effective, it showed from the amount of adsorption capacity was $3.486 \mathrm{mg} / \mathrm{g}$. Furthermore, the use of activation time for activated carbon in this study was shorter a minute than previous study.

\subsection{Adsorption kinetics}

In order to measure of the adsorption uptake with concern to time at a constant pressure or concentration, both pseudo-first-order and pseudosecond-order was applied. Also to determine the diffusion of adsorbate in the pores.

The equation for pseudo-first-order kinetic is illustrated as follows:

$\log \left(q_{e}-q_{t}\right)=\log q_{e}-\frac{k_{1}}{2.303} t$

where $q t$ and $q$ e are the total of MB adsorbed $(\mathrm{mg} / \mathrm{g})$ at time $t(\mathrm{~min})$ and $k_{1}$ is the equilibrium rate constant of the pseudo-first-order (/min).

Fig 7 was interpreted that a straight line of regression coefficient were poor liner. The result of $R^{2}$ uptake in the range of 0.938 to 0.975 .

The pseudo-second-order equation is expressed as follows:

$\frac{t}{q_{t}}=\frac{1}{h}+\frac{1}{q_{e}} t$

while $1 / \mathrm{h}$ was intraparticle diffusion models and $t$ is the contact time. Then a straight line between $t / q t$ versus $t$ gives the value of the constants $k_{2}(\mathrm{~g} / \mathrm{mg} \mathrm{h})$, $q$ e $(\mathrm{mg} / \mathrm{g})$, respectively can be calculated. The constant $k_{2}$ is used to count the initial sorption of MB rate $h$, at $t \rightarrow 0$, can be expressed:

$h=k_{2} q_{e}^{2}$

From the table 1, It conformity between the experiment and the calculation qe value for pseudo second order (Fig.8). Furthermore, all of the coefficient regression were close to unity, its indicate that the adsorption of MB was match with this model. The value of $\mathrm{k} 2$ for removal MB was found decrease. Its due to greater competition for the adsorbent site as the initial concentration. [27] 
Table 1. Kinetics model for adsorption of MB

\begin{tabular}{cccccccc}
\hline \multirow{2}{*}{$\begin{array}{c}\text { Impregnation Ratio of } \\
\text { Activated Carbon : KOH }\end{array}$} & $\begin{array}{c}\mathrm{q}_{\mathrm{e}(\mathrm{exp})} \\
(\mathrm{mg} / \mathrm{g})\end{array}$ & $\mathrm{qe}_{\text {cal }}(\mathrm{mg} / \mathrm{g})$ & $\begin{array}{c}\mathrm{k}_{1} \\
(\mathrm{mg} / \mathrm{m})\end{array}$ & $\mathrm{R}^{2}$ & $\begin{array}{c}\mathrm{q}_{\mathrm{e}(\mathrm{cal})} \\
(\mathrm{mg} / \mathrm{g})\end{array}$ & $\begin{array}{c}\mathrm{k}_{2} \\
(\mathrm{~g} / \mathrm{mg} \cdot \mathrm{min})\end{array}$ & $\mathrm{R}^{2}$ \\
\cline { 3 - 8 } & 3.050 & 0.0487 & 1.3933 & 0.9755 & 3.5050 & 0.0250 & 0.9990 \\
$1: 1$ & 3.486 & 0.0203 & 0.2054 & 0.9385 & 3.7119 & 0.0638 & 0.9969 \\
$1: 2$ & 2.851 & 0.0333 & 0.1837 & 0.9580 & 3.0854 & 0.0406 & 0.9905 \\
$1: 2.5$ & 2.971 & 0.0487 & 0.1393 & 0.9755 & 3.2082 & 0.0624 & 0.9752 \\
\hline
\end{tabular}

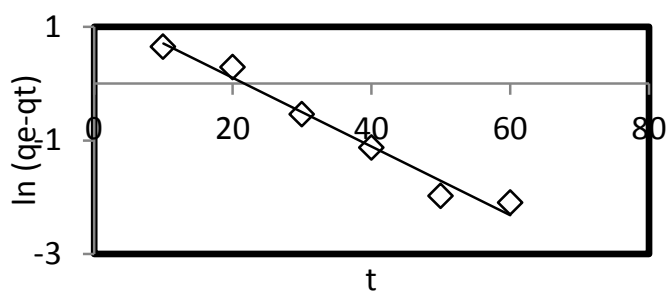

(a)

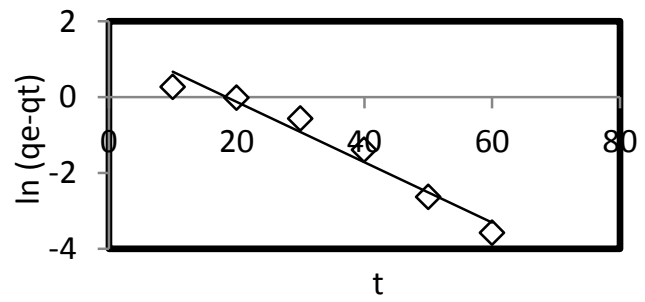

(c)

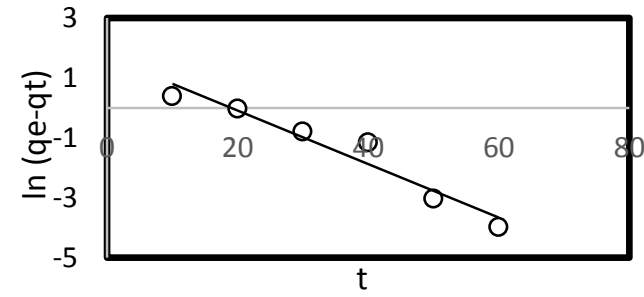

(b)

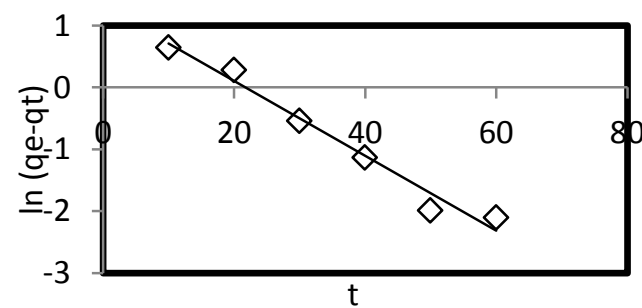

(d)

Fig. 7 Pseudo-first-order kinetic model (a) 1:1 (b) 1:1.5 (c) 1:2 (d) 1:2.5

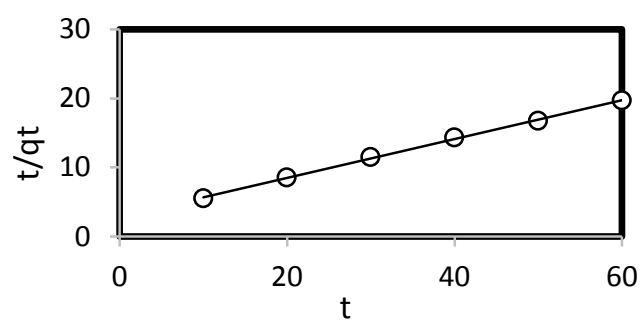

(a)

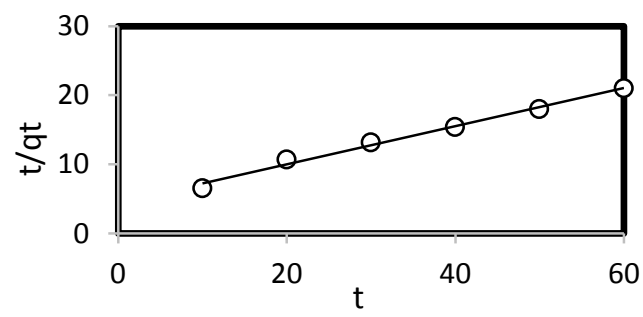

(c)

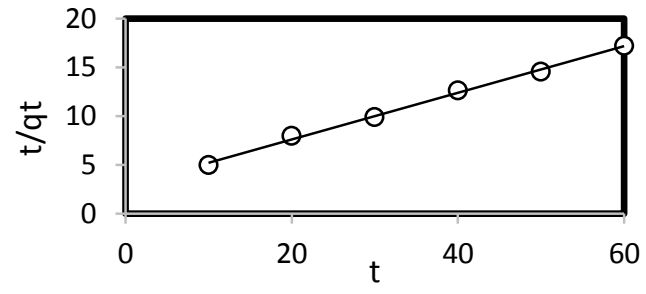

(b)

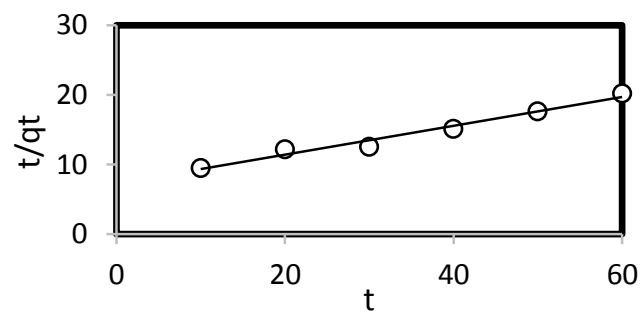

(d)

Fig. 8 Pseudo-second-order kinetic model (a) 1:1 (b) 1:1.5 (c) 1:2 (d) 1:2.5

The highest number of regression coefficient in pseudo second order was 0.9990. From table 1 the similarity number of $\mathrm{q}_{\mathrm{e}}$ (exp) and $\mathrm{q}_{\mathrm{e}}$ (cal) in pseudo second order may conclude that this study was fitting with pseudo second order.

\section{Conclusion}

The rubber seed could be effective and low cost material for preparation as an activated carbon. This study to acknowledge that the utilize of microwave heating radiation for activated carbon 
obtained optimal absorption in wastewater treatment containing dyes. Also the time to activated the carbon shorter than using conventional heating. Furthermore, the result of capacity adsorption in IR 1:1.5 higher than IR 1:2.5, which mean only in a small amount of activator used in adsorption process.

The adsorption isotherm study shows that its suitable with both Freundlich and Langmuir isotherm model. On kinetics data model appeared that the number of qe $($ exp $)$ approach qe $\left({ }_{\text {cal }}\right)$, which conclude that this work was well fitted with pseudo second order.

\section{References}

[1] B.H. Hameed, F.B.M. Daud, Adsorption studies of basic dye on activated carbon derived from agricultural waste: Hevea brasiliensis seed coat, Chemical Engineering Journal, 139 (2008) 48 55.

[2] T.K. Sen, S. Afroze, H.M. Ang, Equilibrium, Kinetics and Mechanism of Removal of Methylene Blue from Aqueous Solution by Adsorption onto Pine Cone Biomass of Pinus radiata, Water, Air, \& Soil Pollution, 218 (2011) $499-515$.

[3] Y.Z. Yu, W.L. Hua, Q.J. Hua, Biosorption of methylene blue from aqueous solution using a bioenergy forest waste: Xanthoceras sorbifolia seed coat, CLEAN - Soil, Air, Water, 37 (2009) 642-648.

[4] M. Rafatullah, O. Sulaiman, R. Hashim, A. Ahmad, Adsorption of methylene blue on lowcost adsorbents: A review, Journal of Hazardous Materials, 177 (2010) 70-80.

[5] I.A.W. Tan, B.H. Hameed, A.L. Ahmad, Equilibrium and kinetic studies on basic dye adsorption by oil palm fibre activated carbon, Chemical Engineering Journal, 127 (2007) 111119.

[6] S. Senthilkumaar, P.R. Varadarajan, K. Porkodi, C.V. Subbhuraam, Adsorption of methylene blue onto jute fiber carbon: kinetics and equilibrium studies, Journal of Colloid and Interface Science, 284 (2005) 78-82.

[7] C. Sahoo, A.K. Gupta, A. Pal, Photocatalytic degradation of Methyl Red dye in aqueous solutions under UV irradiation using $\mathrm{Ag}^{+}$doped $\mathrm{TiO}_{2}$, Desalination, 181 (2005) 91-100.

[8] Y. Badr, M.G.A. El-Wahed, M.A. Mahmoud, Photocatalytic degradation of methyl red dye by silica nanoparticles, Journal of Hazardous Materials, 154 (2008) 245-253.

[9] M.T. Yagub, T.K. Sen, H.M. Ang, Removal of cationic dye methylene blue (MB) from aqueous solution by ground raw and base modified pine cone powder, Environmental Earth Sciences, 71 (2014) 1507 - 1519.
[10] M.T. Yagub, T.K. Sen, H.M. Ang, Equilibrium, Kinetics, and Thermodynamics of Methylene Blue Adsorption by Pine Tree Leaves, Water, Air, \& Soil Pollution, 223 (2012) 5267-5282.

[11] J.Z. Guo, B. Li, L. Liu, K. Lv, Removal of methylene blue from aqueous solutions by chemically modified bamboo, Chemosphere, 111 (2014) 225-231.

[12] Y.Ji, Tiehu Li Zhu, X. Wang, Q. Lin, Preparation of activated carbon by microwave heating $\mathrm{KOH}$ activation, Science Direct 254 (2007) 506-512

[13] A. Shukla, Y.H. Zhang, P. Dubey, J.L. Margrave, S.S. Shukla, The role of sawdust in the removal of unwanted materials from water, Journal of Hazardous Materials, 95 (2002) 137152.

[14] M.A.M. Salleh, D.K. Mahmoud, W.A.W.A. Karim, A. Idris, Cationic and anionic dye adsorption by agricultural solid wastes: a comprehensive review, Desalination, 280 (2011) 1-13.

[15] H.M.F. Freundlich, Ober dies adsorption in losungen. Z., Psysical Chemistry, 57 (1906) 385470.

[16] I. Langmuir, The adsorption of gases on plane surfaces of glass, mica and platinum, Journal of The American Chemical Society, 40 (1918) 1361-1403.

[17] K. Mohanty, M. Jha, B.C. Meikap, M.N. Biswas, Biosorption of $\mathrm{Cr}(\mathrm{VI})$ from aqueous solutions by Eichhornia crassipes, Chemical Engineering Journal, 117 (2006) 71-77.

[18] V. Vimonses, S. Lei, B. Jin, C.W.K. Chowd, C. Saint, Kinetic study and equilibrium isotherm analysis of Congo Red adsorption by clay materials, Chemical Engineering Journal, 148 (2009) 354-364.

[19] S. Dawood, T.K. Sen, Removal of anionic dye Congo red from aqueous solution by raw pine and acid-treated pine cone powder as adsorbent: Equilibrium, thermodynamic, kinetics, mechanism and process design, Water Research, 46 (2012) 1933-1946.

[20] Alslaibi TM, Abustan I, Ahmad MA, Abu Foul A. Review : Comparison of Agricultural by products activated carbon production methods using surface area response. Caspin J Appl Sci Res.2013;2:18-27.

[21] Alslaibi TM, Abustan I, Ahmad MA, Abu Foul A. Review : Production of activated carbon from agricultural by products via conventional and microwave heating. J Chem Technol Biotechnol. 2013; 88 (7) : 1183 - 1190.

[22] Z. Ioannou, C. Karasavvidis, A. Dimirkou, V. Antoniadis, Adsorption of methylene blue and methyl red dyes from aqueous solutions onto 
modified zeolites, Water Science and Technology, 67 (2013) 1129-1136.

[23] Franca,A.S, Olivera, L.S, Nunes, A.A, Alves, C.C.O., 2010. Microwave assisted thermal treatment of defective coffee beans press cake for the production of adsorbents, Bioresour, Technol, 101, 1068-1074.

[24] K.Y.Foo, B.H.Hameed, Recent development in the preparation and regeneration of activated carbons by microwaves, Adv. Colloid Interface Sci.149 (2009) 19-27.
[25] T.S.Hui, M.A.A Zaini, Pottasium Hydroxide activation of activated carbon. Carbon letters 16, 4, 275-280 (2015).

[26] Bandyopadhyay,A., Biswas,M.N,.1998. Removal of hextavalent chromium by synergism modified adsorption. Indian.J. Environ. Prot. 18, 662-671.

[27] M.A. Ahmad, N.A.A Puad, O.S. Belo., 2014. Kinetic, equilibrium and thermodynamics studies of synthetic dye removal using pomegranate peel avtivated carbon prepared by microwave-induced $\mathrm{KOH}$ activation. Water Resources and Insutry, 6 (2014) 18-35. 